\title{
Incidence and Prevalence of Herpes Simplex Virus Type 2 Infection in Persons Seeking Repeat HIV Counseling and Testing
}

\author{
KATHERINE R. TURNER, MPH, ${ }^{*}$ WILLI McFARLAND, MD, PHD, ${ }^{\star \dagger}$ TIMOTHY A. KELLOGG, MA, ${ }^{*}$ ERNEST WONG, BS, \\ KIMBERLY PAGE-SHAFER, PHD, ${ }^{\dagger}$ BRIAN LOUIE, BA, ${ }^{*}$ JIM DILLEY, MD, ${ }^{\ddagger}$ CHARLOTTE K. KENT, MPH, ${ }^{*}$ AND \\ JEFFREY KLAUSNER, MD, MPH*
}

\begin{abstract}
Background: Voluntary HIV testing sites provide an opportunity to identify and counsel persons with herpes simplex virus type 2 (HSV-2) infection, thereby enhancing the prevention of HSV-2 and HIV infections.
\end{abstract}

Goal and Study Design: Using serologic specimens left over from HIV testing, we measured HSV-2 prevalence and incidence among persons who had repeatedly tested for HIV at anonymous counseling and testing sites in San Francisco during the period October 1997 through March 2000.

Results: The prevalence of HSV-2 infection was $23.5 \%(n=987)$ overall, $28.7 \%$ among women, and $24.1 \%$ among men who have sex with men (MSM). In relation to race/ethnicity, HSV-2 prevalence was highest among African Americans (34.4\%). The incidence of HSV-2 infection ( $n=457$ person-years [PY] of follow-up) was 2.6 per $100 \mathrm{PY}$ overall and 3.1 per 100 PY among MSM. All but one of the HSV-2 seroconversions occurred among MSM. In multivariate subanalysis of MSM, a self-reported sexually transmitted disease (hazards ratio [HR], 4.3; 95\% CI, 1.2-16.1) and HIV seroconversion (HR, 19.4; 95\% CI 3.8-99.9) during the interval between tests were correlated with HSV-2 incident infection.

Conclusion: Offering HSV-2 serologic counseling and testing at HIV counseling and testing sites might help prevent the spread of both infectious diseases.

HERPES SIMPLEX VIRUS TYPE 2 (HSV-2) causes one of the most prevalent sexually transmitted diseases (STDs), infecting an estimated $22 \%$ of persons in the United States. ${ }^{1} \mathrm{HSV}-2$ incidence estimates range from 0.8 to 5.1 per 100 person-years., ${ }^{2,3}$ Most persons are unaware of their infection. ${ }^{1,3-6}$

Commercially available type-specific serologic assays present the opportunity to offer HSV-2 testing in diverse settings providing services to populations at risk for other STDs. ${ }^{7-10}$ HIV counseling and testing sites might be particularly desirable venues for HSV-2 screening because of the strong, causal association between HSV-2 and HIV transmission. ${ }^{11-13}$ Persons can be counseled on treatment options and preventive measures to reduce further spread of both infections, including condom use, avoiding sex when symptoms are present, and HSV-2 antiviral therapy to reduce viral shedding during outbreaks. ${ }^{14-16}$ As a first step toward considering whether San Francisco's anonymous HIV counseling and testing sites would be appropriate venues for wider HSV-2 testing, we estimated the prevalence, incidence, and correlates of HSV-2 in-

Reprint requests: Willi McFarland, MD, PHD, 25 Van Ness Avenue, Suite 500, San Francisco, CA 94102-6033. E-mail: willi.mcfarland@ sfdph.org Received July 5, 2002, revised September 5, 2002, and accepted September 23, 2002.
From the *San Francisco Department of Public Health and the ${ }^{+}$Center for AIDS Prevention Studies and ${ }^{\ddagger}$ AIDS Health Project, University of California, San Francisco, California

fection by testing leftover sera from persons repeatedly tested for $\mathrm{HIV}$ at all anonymous testing sites in the city.

\section{Methods}

Subjects

Subjects were persons who sought routine testing for HIV antibodies at anonymous HIV testing locations in San Francisco two or more times from October 1997 through March 2000. We selected repeating testers as the study population because multiple specimens submitted at different points in time provide a basis for estimating the rate of HSV-2 seroconversion (i.e., HSV-2 incidence). ${ }^{17}$ We determined HSV-2 prevalence for 987 persons who provided blood samples at their first testing visit during the study period. HSV-2 incidence was estimated among the 542 persons whose initial HSV-2 tests were negative and who provided a second blood sample at a subsequent visit during the study period. Persons providing oral fluid specimens for HIV testing were not included.

Demographic and risk behavior information was collected on a form routinely completed during each HIV counseling and testing session and was entered into a database. To assess baseline correlates of prevalent infection, we used data reported for the year preceding the first visit. To assess correlates of HSV-2 seroconversion, we used data collected at the last visit reported for the time period most closely corresponding to the interval between tests. The median interval between tests was 9 months (range, 1-28 months).

\section{Unique Testing Code}

Specimens and data from individual repeating anonymous testers were linked by a nonidentifying unique testing code (UTC). ${ }^{18}$ At each visit to an anonymous testing site in San Francisco, clients are routinely asked to create a UTC by using a combination of letters and numbers based on personal information that can be easily and consistently recalled. To identify repeating testers, we matched forms that had the same UTC and had consistent demographic information. We verified that matched specimens originated from the same person by testing a subsample of 
TABLE 1. Prevalence of Herpes Simplex Virus Type 2 (HSV-2) Infection Among Persons Seeking Repeated Anonymous HIV Testing in San Francisco, 1997-2000

\begin{tabular}{|c|c|c|c|}
\hline Variable & $\mathrm{n}$ & $\begin{array}{c}\text { No. } \\
\text { HSV-2-Positive } \\
\text { (Prevalence, } \\
\%)\end{array}$ & $\begin{array}{c}\text { Unadjusted } \\
\text { OR } \\
(95 \% \mathrm{Cl})\end{array}$ \\
\hline Total & 987 & $232(23.5)$ & - \\
\hline \multicolumn{4}{|l|}{ Sex/sexual orientation } \\
\hline $\begin{array}{l}\text { Heterosexual men } \\
\text { Men who have sex }\end{array}$ & 92 & $12(13.0)$ & Referent \\
\hline with men & 752 & $181(24.1)$ & $2.1(1.1-4.2)$ \\
\hline Women & 136 & 39 (28.7) & $2.7(1.3-5.8)^{*}$ \\
\hline \multicolumn{4}{|l|}{ Race/ethnicity } \\
\hline Asian/Pacific Islander & 76 & $10(13.2)$ & Referent \\
\hline Hispanic/Latino & 73 & 17 (23.3) & $2.0(0.8-5.2)$ \\
\hline White, non-Hispanic & 756 & $186(24.6)$ & $2.2(1.1-4.6)$ \\
\hline African American & 35 & $11(34.4)$ & $3.0(1.0-8.9)$ \\
\hline \multicolumn{4}{|l|}{ Age group (y) } \\
\hline$<29$ & 294 & 33 (11.2) & Referent \\
\hline 30-39 & 449 & 95 (21.2) & $2.1(1.4-3.3)$ \\
\hline$>40$ & 239 & $102(42.7)$ & $5.9(3.7-9.4)^{\star}$ \\
\hline \multicolumn{4}{|l|}{$\begin{array}{l}\text { No. of sex partners in } \\
\text { past year }\end{array}$} \\
\hline $0-1$ & 96 & $19(19.9)$ & Referent \\
\hline $2-5$ & 388 & $82(21.1)$ & $1.1(0.6-1.9)$ \\
\hline$>5$ & 481 & $124(25.8)$ & $1.4(0.8-2.5)$ \\
\hline \multicolumn{4}{|l|}{$\begin{array}{l}\text { Self-reported STD in } \\
\text { past year }\end{array}$} \\
\hline No & 880 & 207 (23.5) & Referent \\
\hline Yes & 107 & $25(23.4)$ & $1.0(0.6-1.6)$ \\
\hline \multicolumn{4}{|l|}{$\begin{array}{l}\text { Unprotected insertive } \\
\text { anal sex in past year }\end{array}$} \\
\hline No & 655 & $154(23.5)$ & Referent \\
\hline Yes & 332 & 78 (23.5) & $1.0(0.7-1.4)$ \\
\hline \multicolumn{4}{|l|}{$\begin{array}{l}\text { Unprotected receptive } \\
\text { anal sex in past year }\end{array}$} \\
\hline No & 742 & $163(22.0)$ & Referent \\
\hline Yes & 245 & $69(28.5)$ & $1.4(1.0-1.9)^{*}$ \\
\hline \multicolumn{4}{|l|}{$\begin{array}{l}\text { Sex with HIV-positive } \\
\text { partner in past year }\end{array}$} \\
\hline No/unknown & 676 & $157(23.2)$ & Referent \\
\hline Yes & 311 & $75(24.1)$ & $1.1(0.8-1.4)$ \\
\hline \multicolumn{4}{|l|}{ HIV-positive at baseline } \\
\hline No & 949 & 221 (23.3) & Referent \\
\hline Yes & 38 & $11(29.0)$ & $1.3(0.7-2.7)$ \\
\hline
\end{tabular}

*In multivariate analysis, female sex (OR, 2.3; 95\% Cl, 1.5-3.7), older age (OR, 1.09 per year; $95 \% \mathrm{Cl}, 1.07-1.11)$, and unprotected receptive anal sex in the past year (OR, 1.9; 95\% Cl, 1.3-2.8) were independently and significantly correlated with HSV-2 prevalence.

UTC-paired specimens with a human antibody fingerprinting method. ${ }^{19}$ Of the 45 matched specimens assayed, 43 (96\%) were considered to be from the same person. The Committee for Human Research of the University of California-San Francisco deemed the protocol exempt from the requirement of written informed consent because the UTC system precluded linkage of data to individuals and HSV-2 testing was performed on existing specimens.

\section{HSV-2 Laboratory Methods}

Sera were tested for HSV-2 antibody with an HSV-2 enzymelinked immunosorbent assay (ELISA; Focus Technologies, Cypress, CA). The test uses recombinant HSV-2 gG2 antigen to identify HSV-2 antibody. In a study conducted in our laboratory, sensitivity of the assay was $97.7 \%$ and specificity was $95 \% .{ }^{10}$

\section{Analysis}

We defined HSV-2 seroconverters as persons who were HSV2-negative at their first test and whose subsequent test was positive for HSV-2. HSV-2 incidence was calculated as the number of seroconversions divided by the sum of person-years (PY) of follow-up. For persons who remained uninfected with HSV-2, we calculated PY as the sum of the intervals of time from the first HSV-2-negative test to the most recent HSV-2 test. For seroconverters, we used the midpoint between the last negative test and first HSV-2-positive test to calculate PY.

We calculated HSV-2 prevalence and incidence for subgroups of testers by demographic characteristics and behavioral risk information. Correlates for HSV-2 prevalence were identified by logistic regression analysis. Correlates of HSV-2 incidence were assessed by Cox proportional hazards analysis. The proportionality assumption was verified by using log-log survival plots. ${ }^{20}$ To determine independent associations with HSV-2 prevalence and seroconversion, we entered variables with $P<0.1$ in bivariate analysis into multivariate models. A best subsets analysis, a forward stepwise process, and backward stepwise process converged on the same final models. Age and number of sex partners were treated as continuous variables in multivariate analysis. Statistical analyses were performed with SAS software (SAS Institute, Cary, NC). Confidence intervals were based on the Poisson distribution.

\section{Results}

Of 987 subjects included in the analysis of HSV-2 prevalence, $752(76.2 \%)$ were men who have sex with men (MSM), 143 $(14.5 \%)$ were women, and $92(9.3 \%)$ were heterosexual men. The median age was 32 years (range, $18-71$ years); $756(76.6 \%)$ were of white non-Hispanic ethnicity. In the previous year, 107 (10.8\%) self-reported an STD; 481 (48.7\%) had more than 5 sex partners; $311(31.5 \%)$ had sex with an HIV-infected partner; and 245 $(24.8 \%)$ had unprotected receptive anal sex. A total of 38 subjects (3.9\%) tested HIV-positive.

\section{HSV-2 Prevalence}

Two hundred thirty-two subjects $(23.5 \%)$ were HSV-2 antibody-positive at the time of the first test. HSV-2 prevalence in relation to demographic characteristics and sexual risk behaviors is presented in Table 1. In multivariate analysis, female sex (OR, 2.3; 95\% CI, 1.5-3.7), older age (OR, 1.09 per year; 95\% CI, $1.07-$ 1.11 ), and unprotected receptive anal intercourse (OR, 1.9; $95 \%$ CI, 1.3-2.8) remained significant, independent correlates of prevalent HSV-2 infection.

\section{HSV-2 Incidence}

For the 542 subjects who were initially HSV-2-negative and subsequently provided a serological specimen accounted for 457 PY of follow-up. Twelve HSV-2 seroconversions were identified, yielding an overall incidence of HSV-2 infection of 2.6 per $100 \mathrm{PY}$ (95\% CI, 1.3-4.5). Eleven of the $12 \mathrm{HSV}-2$ seroconversions occurred in MSM (incidence of 3.1 per $100 \mathrm{PY}$; 95\% CI, 0.342.5). The remaining incident infection occurred in a female (incidence of 1.8 per $100 \mathrm{PY}$; 95\% CI, 0.04-9.8).

We conducted a subanalysis of HSV-2 seroconversion in MSM $(n=408)$. Bivariate correlates of HSV-2 seroconversion for MSM are presented in Table 2 . In multivariate analysis, a self-reported history of any STD (HR, 4.3; 95\% CI, 1.2-16.1) and HIV seroconversion (HR, 19.4; 95\% CI, 3.8-99.5) during the interval between tests were correlated with HSV-2 seroconversion. Because these men had both infections identified at the same test, the 
TABLE 2. Incidence of Herpes Simplex Virus Type 2 (HSV-2) Infection Among Men Who Have Sex with Men (MSM) Seeking Repeated HIV Testing, San Francisco, 1997-2000

\begin{tabular}{|c|c|c|c|c|}
\hline Variable & $\begin{array}{l}\text { Person-Years } \\
\text { (PY) }\end{array}$ & $\begin{array}{c}\text { HSV-2 } \\
\text { Seroconversions }\end{array}$ & $\begin{array}{c}\text { HSV-2 } \\
\text { Incidence/100 PY }\end{array}$ & $\begin{array}{c}\text { Unadjusted } \\
\text { Hazard Ratio } \\
(95 \% \mathrm{Cl})\end{array}$ \\
\hline \multicolumn{5}{|l|}{ Race/ethnicity } \\
\hline Nonwhite & 54.1 & 1 & 1.8 & - \\
\hline White & 278.5 & 8 & 2.9 & $1.5(0.2-11.7)$ \\
\hline \multicolumn{5}{|l|}{ Age group (y) } \\
\hline$>40$ & 80.8 & 1 & 1.2 & $0.6(0.1-6.7)$ \\
\hline \multicolumn{5}{|c|}{$\begin{array}{l}\text { No. of sex partners during testing } \\
\text { interval }\end{array}$} \\
\hline $0-1$ & 26.7 & 1 & 3.7 & - \\
\hline $2-5$ & 108.1 & 4 & 3.7 & $1.3(0.1-11.6)$ \\
\hline$>5$ & 216.3 & 6 & 2.8 & $0.9(0.1-7.7)$ \\
\hline No & 216.8 & 7 & 3.2 & - \\
\hline Yes & 139.0 & 4 & 2.9 & $1.1(0.3-3.7)$ \\
\hline \multicolumn{5}{|c|}{$\begin{array}{l}\text { Unprotected receptive anal sex during } \\
\text { testing interval }\end{array}$} \\
\hline No & 262.6 & 6 & 2.3 & - \\
\hline Yes & 93.1 & 5 & 5.4 & $3.0(0.9-10.3)$ \\
\hline \multicolumn{5}{|c|}{$\begin{array}{l}\text { Sex with HIV-positive partner during } \\
\text { testing interval }\end{array}$} \\
\hline No & 213.9 & 4 & 1.9 & - \\
\hline Yes & 141.8 & 7 & 4.9 & $2.6(0.8-8.8)$ \\
\hline \multicolumn{5}{|c|}{ HIV seroconversion at follow-up } \\
\hline No & 349.4 & 9 & 2.6 & - \\
\hline Yes & 6.3 & 2 & 31.6 & $12.8(2.8-59.2)^{*}$ \\
\hline
\end{tabular}

*In multivariate analysis, history of STD (HR, 4.3; 95\% Cl, 1.2-16.1) and HIV seroconversion (HR, 19.4; 95\% Cl, 3.8-99.9) during the interval between tests were independently correlated with HSV-2 seroconversion.

temporal sequence of infection (i.e., which infection was acquired first) could not be established.

\section{HIV Incidence}

We examined HIV seroconversion among MSM who were HIV-negative at baseline and who subsequently retested for HIV, including oral and serological testing. This population's follow-up differed but overlapped that of the MSM included in the analysis of HSV-2 seroconversion. The incidence of HIV infection in this population was 1.8 per $100 \mathrm{PY}(95 \% \mathrm{CI}, 0.8-2.3)$, a figure based on 13 HIV seroconversions. Two of the $11 \mathrm{HSV}-2$ seroconversions occurred in MSM who also seroconverted to HIV. Prevalent HSV-2 infection at baseline was not associated with subsequent HIV seroconversion (OR, 1.0; 95\% CI, 0.3-4.7).

\section{Discussion}

Our study presents a convenient method to estimate HSV-2 prevalence and incidence in an accessible population at risk for STDs with use of existing specimens linked through an anonymous UTC. Estimates of HSV-2 incidence, usually determined in longitudinal cohort studies, are rare.

The prevalence of HSV-2 infection in this sample was similar to estimates for the general United States population. ${ }^{1}$ Prevalence among MSM in our study $(24.1 \%)$ was lower than a previous estimate for San Francisco in 1989 (40\%) but similar to a more recent estimate for MSM in Seattle (26\%). ${ }^{21,22}$ Among women in our sample, HSV-2 prevalence $(28.7 \%)$ was lower than that found in a San Francisco Bay Area population-based door-to-door survey of women in low-income neighborhoods $(35 \%) .^{23}$

The rate of HSV-2 seroconversion estimated in our study (2.6 per $100 \mathrm{PY}$ overall) was lower than observed in a prospective study of persons at high risk for HSV-2 (5.1 per $100 \mathrm{PY}$ ) but higher than in a study of the general population in 1985 (0.8 per 100 PY). ${ }^{2,3}$ Our observed HSV-2 incidence among MSM (3.1 per 100 PY) was substantially higher than that in a cohort of MSM in Seattle (1.0 per 100 PY). ${ }^{22}$ Among MSM, history of STD and seroconversion for HIV were strong independent correlates of HSV-2 acquisition.

We recognize limitations to our study. We examined persons repeatedly tested for HIV, who may not be representative of once-only HIV testers or of persons not seeking testing at all. Persons repeatedly seeking HIV testing may be more likely to engage in unprotected sex and therefore may be at higher risk for HSV-2 than other populations. Moreover, we could not include persons electing oral fluid HIV testing. Our risk behavior information came from self-reported behavioral data collected for the purpose of HIV counseling. These data are not always collected consistently or completely. Additionally, the data collection instrument did not delineate specific STDs or 
history of genital ulcers. Last, although the accuracy of the UTCs was high (96\%) in identifying repeatedly tested individuals in an anonymous system, there may have been some mismatched specimen pairs.

Despite potential limitations, our data, in conjunction with those from other studies, suggest that HIV testing venues can be appropriate sites for wider screening for HSV-2. Approximately one in four persons in our sample were infected with HSV-2, whereas nearly $4 \%$ were infected with HIV. The rate of HSV-2 acquisition was also higher than the rate of HIV acquisition. Given the high prevalence and incidence of HSV-2 in the HIV testing population and the strong evidence causally linking HIV and HSV-2, wider counseling and testing for HSV-2 at HIV testing sites can substantially contribute to the control of both infections. Offering HSV-2 counseling and testing to women, MSM, persons reporting a history of other STDs, and those who are HIV-positive might be particularly effective.

\section{References}

1. Fleming DT, McQuillan GM, Johnson RE, et al. Herpes simplex virus type 2 in the United States, 1976 to 1994. N Engl J Med 1997; 337:1105-1111.

2. Armstrong GL, Schillinger J, Markowitz L, et al. Incidence of herpes simplex virus type 2 infection in the United States. Am J Epidemiol 2001; 153:912-920.

3. Langenberg AG, Corey L, Ashley RL, Leong WP, Straus SS. A prospective study of new infections with herpes simplex virus type 1 and 2. N Engl J Med 1999; 341:1432-1438.

4. Wald A, Zeh J, Selke S, et al. Reactivation of genital herpes simplex virus type 2 infection in asymptomatic seropositive persons. $\mathrm{N}$ Engl J Med 2000; 342:844-850.

5. Langenberg A, Benedetti J, Jenkins J, Ashley R, Winter C, Corey L. Development of clinically recognizable genital lesions among women previously identified as having "asymptomatic" herpes simplex virus type 2 infection. Ann Intern Med 1989; 100:882-887.

6. Frenkel LM, Garratty EM, Shen JP, Wheeler N, Clark O, Bryson YJ. Clinical reactivation of herpes simplex virus type 2 infection in seropositive pregnant women with no history of genital herpes. Ann Intern Med 1993; 118:414-418.

7. Ashley RL, Wald A, Eagleton M. Premarket evaluation of the POCkit HSV-2 type-specific serologic test in culture-documented cases of genital herpes simplex virus type 2. Sex Transm Dis 2000; 27:266269.

8. Ashley RL, Wu L, Pickering JW, Tu MC, Schnorenberg L. Premarket evaluation of a commercial glycoprotein G-based enzyme immunoassay for herpes simplex virus type-specific antibodies. J Clin Microbiol 1998; 36:294-295.
9. Ashley RL. Type-specific antibodies to HSV-1 and -2: review of methodology. Herpes 1998; 5:33-38.

10. Turner KR, Wong EH, Kent CK, Klausner JD. Serologic herpes testing in the real world: validation of new type-specific serologic herpes simplex virus tests in a public health laboratory. Sex Transm Dis 2002; 29:422-425.

11. Fleming DT, Wasserheit JN. From epidemiological synergy to public health policy and practice: the contribution of other sexually transmitted diseases to sexual transmission of HIV infection. Sex Transm Infect 1999; 75:3-17.

12. Stamm WE, Handsfield HH, Rompalo AM, Ashley RL, Roberts PL, Lawrence $\mathrm{C}$. The association between genital ulcer disease and acquisition of HIV infection in homosexual men. JAMA 1988; $1429-1433$.

13. Wald A, Link K. Risk of human immunodeficiency virus infection in herpes simplex virus type- 2 seropositive persons: a meta-analysis. J Infect Dis 2002;185:45-52.

14. Wald A, Langenberg A, Link K, et al. Effect of condoms on reducing the transmission of herpes simplex virus type 2 from men to women. JAMA 2001; 285:3100-3106.

15. Wald A, Zeh J, Barnum G, Davis LG, Corey L. Suppression of subclinical shedding of herpes simplex virus type 2 with acyclovir. Ann Intern Med 1996; 124:8-15.

16. Wald A. New therapies and prevention strategies for genital herpes. Clin Infect Dis 1999; 28:S4-S13.

17. McFarland W, Kellogg T, Dilley J, Katz M. Estimating HIV seroincidence among repeat anonymous testers in San Francisco. Am J Epidemiol 1997; 146:662-664.

18. Dilley J, McFarland W, Kellogg TA, et al. Use of a unique testing code among anonymous testers to track repeat tests, estimate HIV incidence, and identify risk factors for HIV seroconversion [abstract MoPpD1132]. Presented at the 13th International AIDS Conference, Durban, July 2000.

19. Ascher DP, Roberts, C. Determination of the etiology of seroreversals in HIV testing by antibody fingerprinting. J Acquir Immune Defic Syndr 1992; 6:241-244.

20. Katz MH. Multivariate analysis: a practical guide for clinicians. Cambridge: Cambridge University Press, 1999.

21. Siegel D, Golden E, Washington AE, et al. Prevalence and correlates of herpes simplex infections: the population-based AIDS in Multiethnic Neighborhood Study. JAMA 1992; 268:1702-1708.

22. Tabet SR, Krone MR, Paradise MA, Corey L, Stamm WE, Celum CL. Incidence of HIV and sexually transmitted diseases in a cohort of HIV-negative men who have sex with men. AIDS 1998; 12:20412048.

23. Buchacz K, McFarland W, Hernandez M, et al. Prevalence and correlates of herpes simplex virus type 2 infection in a population-based survey of young women in low-income neighborhoods of Northern California. Sex Transm Dis 2000; 27:393-400. 